\title{
Stakeholders' responsibilities in reverse logistics of product-service systems: towards circular economy in the healthcare industry
}

\author{
Adriana Hofmann Trevisan ${ }^{1 *}$, Daniel Guzzo ${ }^{2}$, Sânia da Costa Fernandes ${ }^{1,3}$, Henrique Rozenfeld ${ }^{1}$, Monica Rossi ${ }^{4}$, \\ Janaina Mascarenhas ${ }^{1}$ \\ ${ }^{1}$ Department of Production Engineering, São Carlos School of Engineering, Universidade de São Paulo - USP, São Carlos, SP, Brasil \\ ${ }^{2}$ Technical University of Denmark, Copenhagen Metropolitan Area, Denmark \\ ${ }^{3}$ Universidade Presbiteriana Mackenzie, Campinas, SP, Brasil \\ ${ }^{4}$ Department of Economics, Management and Industrial Engineering, Politecnico di Milano, Milano, Italy
}

\begin{abstract}
Reverse logistic system is essential in Product-Service Systems (PSS), which have been labeled as a means to achieve the circular economy. Multiple stakeholders should be involved in the design and operation of the reverse logistics system, but their responsibilities are not clearly consolidated yet. The identification of stakeholders and their responsibilities is even more important in complex sectors that involve the regulation of products and unique services, such as the healthcare industry. This paper aims to consolidate the reverse logistics services and the stakeholders' responsibilities based on two PSS cases in medical devices companies in the context of circular economy. Based on case studies, two maps of stakeholders' responsibilities are presented to support the operation of reverse logistics networks. The companies should have a systemic perspective of the several stakeholders instead of focusing only on limited relationships based on the customer and the PSS provider. Also, take-back activities should be considered since the middle-of-life of products, and all products should be part of the reverse logistics system to lead to the circularity of materials.
\end{abstract}

Keywords: product-service system, circular economy, medical devices, reverse logistics, sustainability.

\section{Introduction}

The Circular economy aims to dissociate the global production and consumption from the linear economic model (grounded on the take-make-dispose) while steering it towards an economy based on the continuous circularity of resources (Ellen MacArthur Foundation, 2013). According to Rosa et al. (2019), Product Service Systems (PSS) business model has the potential to achieve the CE as PSS can increase product recovery level. In this context, Reverse Logistics (RL) system becomes essential. RL supports recovering, reusing, remanufacturing/refurbishment, recycling, and appropriate disposal of products and their components (Chierici \& Copani, 2016). RL operations strongly depend on the relationship established among different stakeholders. Users, for instance, can support PSS providers by using postal service to return used products rather than waiting for the Company to collect them (Wastling et al., 2018). Companies can select third-party RL providers to collect products already used by customers (Govindan et al., 2012). Overall, partners are essential for closing the resource loop and ensuring a reliable product recovery system in PSS offers (Sousa-Zomer et al., 2018), as required for a $\mathrm{CE}$.

Despite the importance of different stakeholders to design and operate PSS business model (Fernandes et al., 2019), the discussion about their responsibilities to conduct RL activities are still incipient in the literature. Especially in the healthcare sector, further investigation on PSS solutions becomes necessary as healthcare providers converge to service-based offers in multi-stakeholders highly regulated settings (Yip et al., 2015). According to Mun \& Kantrowitz (2008), nurses can spend up 40\% of their working time locating equipment. This reinforces the need to know where the equipment is and who is responsible for providing products recovery and maintenance services to make them available for use again. Communication between stakeholders and the responsibilities shared by them is also essential to ensure the safety and proper functioning of medical devices (World Health Organization, 2003). For example, if a medical device fails, the user should know which stakeholders are responsible for carrying out the maintenance to avoid equipment unavailability and, consequently, prevent harm to patients. Furthermore, having a general understanding of the processes required

Received: June 7, 2021. Accepted: February 4, 2022.

*Corresponding author: Adriana Hofmann Trevisan. E-mail: adrianatrevisan@usp.b 
to deliver the PSS solution (including the RL) can help providers improve their customer experience (Azzine Shiratori et al., 2021) and better choose their partners. Given this background, it's essential to expand the body of knowledge on how these players engage in RL activities to collect and process medical devices within PSS.

Based on that, we analyzed RL activities involving different stakeholders through case studies of two medical device companies in Brazil. According to the Brazilian Medical Devices Manufacturers Association (Associação Brasileira da Indústria de Dispositivos Médicos, 2021), the Brazilian market for medical devices is worldwide expressive, and the consumption of products has been growing gradually in recent years (an expansion of $17.4 \%$ in 2020 compared to 2019). Despite the size of this market, and the importance of operating end-of-life strategies to medical devices, scholars offer little guidance on how LR activities are conducted in service-based business models in the healthcare area. To the best of authors knowledge, PSS of medical equipment in the Brazilian context has been totally missed in the current PSS, Servitization, and CE literature. Regarding the PSS domain, the responsibilities assumed by the stakeholders in RL process to foster circularity are rarely mentioned. Therefore, this study consolidates the stakeholder's responsibilities directly involved in the RL operation in PSS solutions that lead to the circularity of the medical devices. We address the following research questions: (I) Which services within a PSS require RL system to foster circularity in the healthcare industry? (II) Which stakeholders (e.g., individuals or organizations) are involved in these services? (III) What are the stakeholders' responsibilities in operating RL on the PSS of medical devices in the CE context?

Based on empirical evidence, this study provides four main contributions. First, we present two maps of stakeholder responsibilities with each agent's interactions and interdependencies in the RL of medical devices. Second, we emphasize some important contingency factors that should be considered when defining responsibilities. Also, we highlight the importance of carrying out product take-back activities not only at the end of life (EOL) stage but also during the middle of life (MOL). Finally, we discuss that all components or products should be part of the RL system to reach CE, not only those with higher added value.

\section{Conceptual background}

\subsection{Reverse logistics and Product-Service Systems}

The adoption of take-back strategy is crucial to implement sustainable oriented product-service system (Guzzo et al., 2019). In this regard, several services can be offered, such as maintenance support, system's installation, user training, and upgrades (Azzine Shiratori et al., 2021). Some of these services involve take-back activities and, hence, demand RL infrastructure. According to Fleischmann et al. (2000), a RL system is characterized by five specific and recurrent activities: (I) Collection: activities to collect physical product from the market; (II) Inspection/separation: operations that determine if a product can surely be reused (or disposed of) and how; (III) Re-processing: the transformation of a used product into a reusable one; (IV) Disposal: discarding of non-recoverable products due to technical or economic constraints; (V) Redistribution: redirect the recovered product to potential markets that can make it available to new users.

Regarding the RL of medical devices in PSS business models, limited research is available to date. Damha et al. (2019) analyzed six cases of medical devices PSS and discussed the EOL strategies applied to this specific industry. Xing et al. (2017) conducted a systematic review process and identified 23 research on PSS in healthcare. However, only two of them (i.e. Moultrie et al., 2015; Pourabdollahian \& Copani, 2015) address healthcare devices. On top of that, the studies do not mention RL activities. A logistical infrastructure is needed to return the product to the owner for further activities that add value to the used product (Feist, 2021). For instance, Through the RL system, PSS suppliers can update product performance and plan an appropriate remanufacturing process (Copani \& Behnam, 2020). These activities is totally in line with a business model pursuing a CE (Han et al., 2020).

\subsection{PSS business models for Circular Economy}

The potential of PSS solutions to conduct business transitions to a CE is frequently discussed in literature (Rosa et al., 2019). Gnoni et al. (2017) analyzed a CE-oriented PSS case and presented several benefits related to the three pillars of sustainability (economic, social and environmental). Specific requirements to enable CE through PSS solutions are provided by Kjaer et al. (2019). Guzzo et al. (2019) demonstrated that PSS business models make systematic use of circular strategies. Fernandes et al. (2020) present an integrated view of the guiding principles adopted when designing PSS oriented to CE.

Although integrated product-service offering is preferable and presents greater economic and environmental advantages, not all PSS types can be considered circular (Tukker, 2015). For instance, in Product-oriented PSS, the customers buy the product, and the provider offers additional services, such as take-back services after-sales for potential product upgrades (Kjaer et al., 2019). For User-oriented type, the offer is developed mainly around 
the product, but it remains the PSS provider's property. RL systems are rather critical in this configuration since it is the Company's responsibility to collect the product (Kjaer et al., 2019). For Result-oriented service, the user's needs are fulfilled through the product's functionality and performance. In this case, the responsibility relies entirely on the provider (Meier et al., 2010) that, in turn, is interested in maintaining the products' lifespan as long as possible (Kjaer et al., 2019). Thus, many authors state that result-oriented PSS is the most strategic way to achieve a CE model (Pialot et al., 2017; Tukker, 2015). RL enables the transportation of products in the opposite direction of the forward supply chain, making it possible to deliver solutions grounded on a circular model.

\section{Research methodology}

The case study methodology was applied to investigate stakeholders' responsibilities to support RL activities in healthcare PSS business models for the CE. This empirical strategy enabled understanding the RL phenomenon in the natural setting, considering its dynamics and complexity. Yin (2009) stated that the case study methodology provides qualitative evidence to generate broad and solid knowledge. Two case studies were conducted employing semi-structured interviews in such a way to collect and consolidate evidence on the RL activities and stakeholders' responsibilities in a PSS context of two medical device companies. The criteria to select the cases were: (i) the cases should be part of the healthcare industry; (ii) RL activities should be provided by them; (iii) each case should present a different PSS business model type. Both selected companies are considered the market leader in Brazil. While Company A is one of the most significant aesthetic equipment manufacturers in the country, Company B stands out in the segment of medical infusion therapy equipment. These companies were attractive to our research because they provide PSS of medical devices, have different partnerships, and carry out LR activities to extend the product lifespan.

\subsection{Research protocol design/data collection}

A research background on RL, PSS, CE, and product life cycle management was conducted to provide a fundamental theoretical basis to design the research protocol (see Appendix 1). The aim of designing the protocol was (I) to gather information about the companies; (II) to understand their PSS business model based on the offering of medical device and related services; (III) to understand their product life cycle and to identify the stakeholders and their responsibilities, specifically focusing on the RL activities.

First, general questions were prepared to identify contextual information, such as the Company's size, product portfolio, number of employees, and the interviewee's role. On a second stage, to understand the business model, questions were defined based on the nine dimensions from the Business Model Canvas (Osterwalder \& Pigneur, 2010), one of the most well-known approaches to describe business solutions. Finally, to identify the stakeholders' responsibilities, the protocol was defined based on the maintenance strategies from Swanson (2001) and the RL activities proposed by Fleischmann et al. (2000), since it is one of the most well-known procedures in this field. The activities consist of collection, inspection/separation, re-processing, disposal, and redistribution (described in section 2).

We conducted two case studies independently, handled through semi-structured interviews, by following the research protocol. Considering that multiple companies are involved in both investigated solutions, from now on, Case A and Case B will be used to refer to each solution (including all stakeholders), while the main providers will be called Company A (for Case A) and Company B (for Case B). In both companies, practitioners with an interface to the RL structure were interviewed. They were the sales and service coordinator, engineering manager, certificate and equipment validation supervisor, technical assistance manager, and quality and regulatory manager. At Company of case A, the product analyzed was medical aesthetic equipment consisting of a physical platform and handpiece lasers (modules) with different dermatology, plastic, and vascular surgery applications. At Company of case B, infusion pump with infusion sets were analyzed. Infusion set attached to the pumps provides fluids to patients' body.

Data collection were carried out in parallel in both companies. Each interview lasted about three hours. The authors employed research diaries to record and process information to compile the verbal responses from interviews, direct observation, and post reflection. After that, a communication channel was kept with the practitioners to clarify further questions.

\subsection{Data analysis}

The data collected were analyzed to enable the consolidation of RL services, stakeholders, and responsibilities related to the RL activities in the healthcare PSS business models for the CE. The evidence from observation and notes was discussed among the researchers, resulting in identifying the individuals and organizations directly 
involved in the services related to the MOL and EOL, a list of responsibilities of each stakeholder, and the crossanalysis of cases considering the scope of PSS and CE.

For each case, two maps were provided. The first one depicts the stakeholders related to the RL activities, which was drafted based on the guidelines set by Stickdorn \& Schneider (2011) and following the information from the companies' business models. The second one represents the services that involve RL activities according to the product life cycle phases and the corresponding responsibility of each stakeholder. This representation was designed according to Fleischmann et al. (2000). Interviewees validated both maps through face-to-face meetings.

\section{Results}

\subsection{PSS cases description}

Company A is located in São Paulo (Brazil), established based on Business to Business (B2B) marketing with clients in Brazil. Company $\mathrm{A}$ is a leader in the aesthetic market. Its main medical equipment consists of a physical platform and a handpiece laser offered to service providers companies, such as dermatologic clinics. Besides selling the product, Company A provides a guarantee and additional services, such as preventive maintenance and parts replacement. The product is modular and presents different life cycles for the two parts that compose it. Specific services are offered for each module. There are two versions of the product (herein called as V1 and V2, respectively). Some modules designed for the new platform (V2) do not apply to the previous one (V1).

Company B is also located in São Paulo (Brazil) and establishes a B2B relationship with its main customers (hospitals). Company B is a market leader in providing infusion systems in Brazil. The infusion system comprises two modules: the infusion pump - a piece of durable equipment, and the infusion sets, which are consumables. Company B's business model consists of continuously selling the consumables for the infusion pumps provided under a lending regime (typically for two years). The Company offers the equipment for its customers at no expense, and the organization profits from the sale of the infusion sets. During custody, the customer needs to keep the medical devices and use them following the guidelines set on the agreement signed. The preventive and corrective maintenances are performed by Company B's employees (in São Paulo) or by third parties (in other areas in Brazil). Upon the contract conclusion, customers must return the infusion pumps to the Company. To guarantee that this business model is profitable, the customer needs to use ten infusion sets every month for each pump provided. Infusion sets are designed for single-use, becoming healthcare waste after use. Moreover, the pump is designed not to be attached to the competitor's infusion sets to keep customer-provider reliance. Table 1 presents a summary of the information to each Company.

Table 1. Characteristics of each case.

\begin{tabular}{|c|c|c|}
\hline & Case A & Case B \\
\hline Business transactions & B2B & B2B \\
\hline Main customer & Dermatologic clinics & Hospitals \\
\hline Product type & Medical dermatological equipment & Infusion pump \\
\hline Product characteristics & $\begin{array}{l}\text { Two versions of the product } \\
\text { Two modules: platform and handpiece }\end{array}$ & $\begin{array}{l}\text { Two modules: Equipment and infusion } \\
\text { sets }\end{array}$ \\
\hline PSS features & Sale and additional services & $\begin{array}{c}\text { Lending scheme, sale of infusion sets, and } \\
\text { additional services }\end{array}$ \\
\hline
\end{tabular}

\subsection{Identification of stakeholders}

Seven stakeholders involved in the RL provided by Company of case A were mapped (Figure 1, left side). In Company A's business model, the technical assistance role is key for the services' conduction. It deals both with the client and with the production line staff for more sophisticated repairs. The transport company (TC) is the only stakeholder directly involved with the client without the Company's mediation since it is responsible for collecting and returning the product. Also, the TC is responsible for redistributing of used products from an old customer to a new one. The waste management company is the one accountable for properly disposing of products' parts and components. A new customer is included when the dermatological platform reaches a second use cycle. 


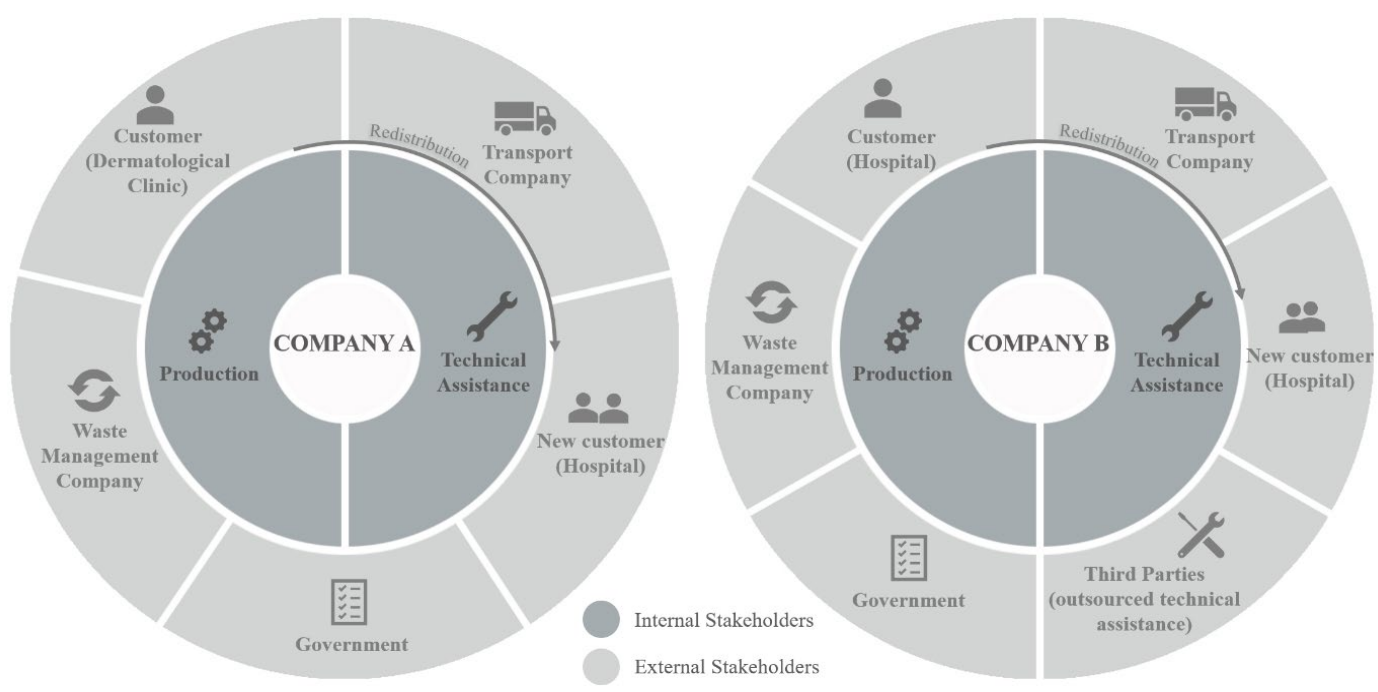

Figure 1. Stakeholder map of medical device in the RL system (Case A and B).

At Company of case B (Figure 1, right side), it is possible to notice outsourced technical assistance (besides the stakeholders mentioned for Company A). The third parties have direct contact with the customers, and in most cases, this agent acts on behalf of Company B in the negotiations. The government, indicated in both maps, plays a relevant role in the RL operation of several products, including electro-electronic components. In 2010, the Brazilian government enacted a National Policy on Solid Waste (law number 12.305/2010) that rules on the shared responsibilities of all the agents involved on the RL, including users, manufacturers, public law, distributors, importers, and traders (Brasil, 2010).

\subsection{Reverse logistics services: Case $A$}

Seven services provided by Company of case A involve RL activities (Figure 2). Four of the services refer to the physical platform and three to the handpiece laser. Similar services related to the platform and the modules were represented separately, as the products have different sizes, with great influence on transportation. For example, even though the platform's and module's preventive maintenance have the same yearly trigger, a technical assistant should visit the customer to calibrate the platform. In contrast, customers send the handpiece laser to the Company. On Figure 2, each stakeholder corresponds to a different color. The description of the responsibilities held by the stakeholders is available in Table 2. Although the government is a decisive stakeholder, its responsibilities have not been represented in Figure 2 and Table 2, as it does not act directly with RL services but as a regulator. Company A provides the following services:

(I) Preventive maintenance - Platform: Yearly manual calibration of the platform defines the start of preventive maintenance. Consumables are replaced according to their lifespan. For this service, RL applies only to parts and consumables;

(II) Corrective maintenance - Platform: User (physician) identification of failure initiates corrective maintenance. If the guarantee still covers the product, Company A sends its technical assistance team and covers the costs. RL relates only to the damaged parts that get back to Company A;

(III) Disposal - Platform: the service starts when repairing the product is not economically feasible for the customer, and warranty coverage has ended. When the product's parts are not obsolete, Company A attempts to recondition them;

(IV) Trade-in - Platform: the service starts when the client has one V1 platform and is interested in purchasing a new version. The used platform is reconditioned and relocated to a new customer, commonly a teaching hospital that purchases the reconditioned platform below market value. However, the trade-in service only happens when the product is not broken beyond repair for technical and economic reasons;

(V) Preventive maintenance - Handpiece laser: the service keeps track of the module's annual calibration. RL relates to the part;

(VI) Corrective maintenance - Handpiece laser: the services start when the user (physician) identifies that the module has stopped working properly. Warranty and service level also apply to the handpiece. The module 
is sent to company $\mathrm{A}$, which repairs it in-house because of its high manufacturing complexity. The customer rented a module while the other is repaired. RL relates to the part;

(VII) Disposal - Handpiece laser: Again, if the repair cost is too high and the Company determines it is not economically viable, the disposal process begins. Anyhow, Company A attempts to recondition/reuse parts that are not obsolete.

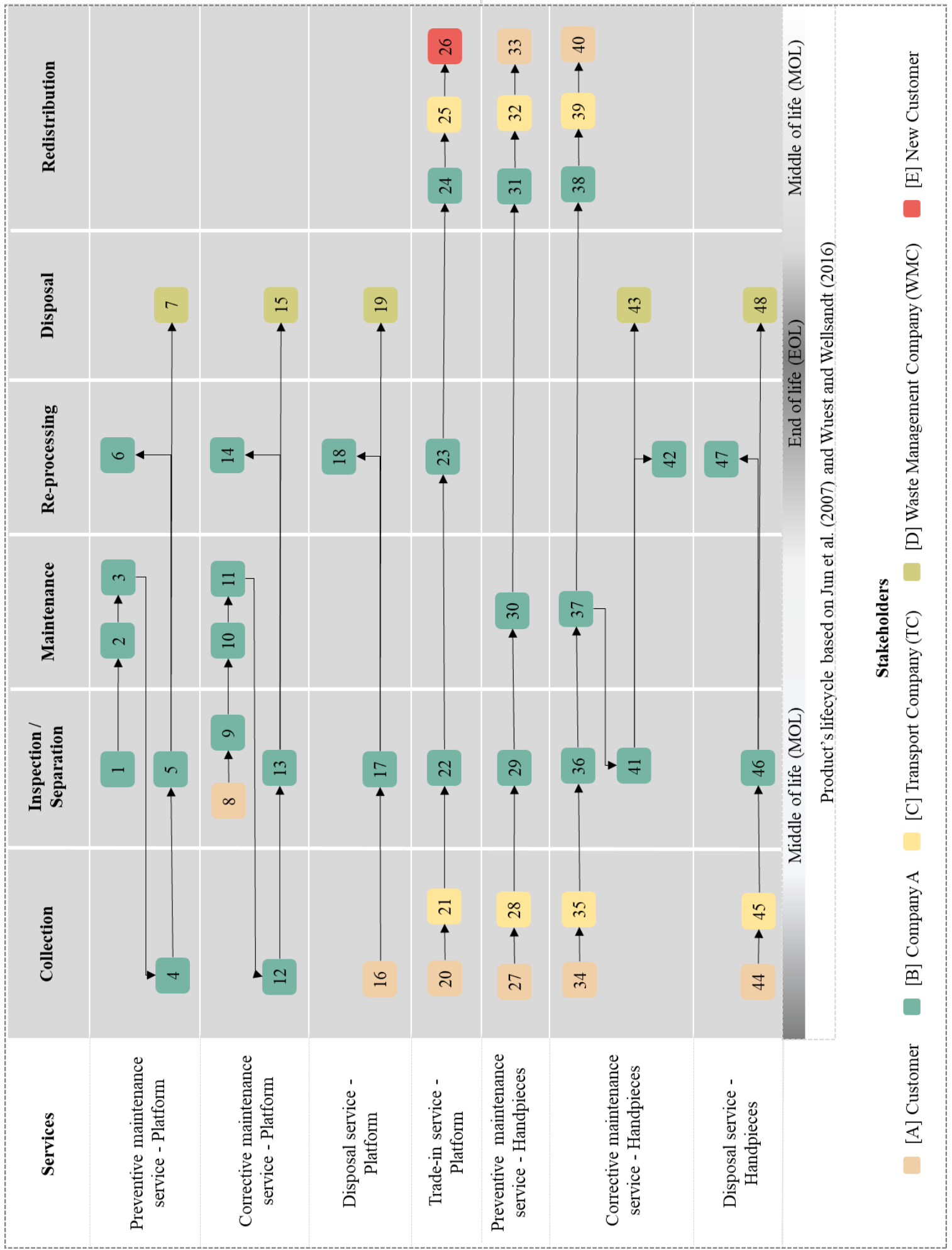

Figure 2. Responsibility map - Case A. 
Table 2. Stakeholder's responsibilities - Case A.

\begin{tabular}{|c|c|c|c|}
\hline \# & ID & Responsibilities & Stakeholder \\
\hline \multirow{7}{*}{ 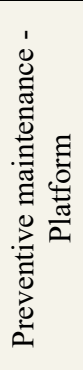 } & 1 & Displace technical assistance to $[\mathrm{A}]$ and inspect the platform in loco & Company A \\
\hline & 2 & Calibrate the platform & Company A \\
\hline & 3 & Replace consumables (according to lifespan) & Company A \\
\hline & 4 & Return consumables to $[\mathrm{B}]$ & Company A \\
\hline & 5 & Inspect and separate parts/consumables & Company A \\
\hline & 6 & Recondition parts/consumables & Company A \\
\hline & 7 & Dispose parts/consumables & WMC \\
\hline \multirow{8}{*}{ 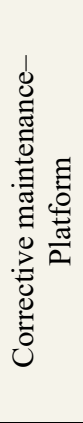 } & 8 & Inform $[\mathrm{B}]$ about the faulty part & Customer \\
\hline & 9 & Displace technical assistance to $[\mathrm{A}]$ and inspect the platform in loco & Company A \\
\hline & 10 & Do the maintenance of the platform & Company A \\
\hline & 11 & Replace faulty parts & Company A \\
\hline & 12 & Return the parts to $[\mathrm{B}]$ & Company A \\
\hline & 13 & Inspect and separate parts and consumables & Company A \\
\hline & 14 & Recondition parts/consumables & Company A \\
\hline & 15 & Dispose parts/consumables & WMC \\
\hline \multirow{4}{*}{ 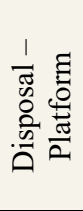 } & 16 & Take the platform to $[\mathrm{B}]$ & Customer \\
\hline & 17 & Inspect and separate parts and consumables & Company A \\
\hline & 18 & Recondition parts/consumables & Company A \\
\hline & 19 & Dispose parts/consumables & WMC \\
\hline \multirow{7}{*}{ 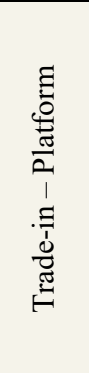 } & 20 & Inform [B] about the wish to replace platform V01 with V02 & Customer \\
\hline & 21 & Deliver platform V02 to [A] and collect platform V01 & TC \\
\hline & 22 & Inspect platform V01 & Company A \\
\hline & 23 & Recondition platform V01 & Company A \\
\hline & 24 & Request transportation of the platform to the $[\mathrm{C}]$ & Company A \\
\hline & 25 & Send the reconditioned platform V01 to the $[\mathrm{E}]$ & $\mathrm{TC}$ \\
\hline & 26 & Receive the reconditioned platform V01 & New Customer \\
\hline \multirow{7}{*}{ 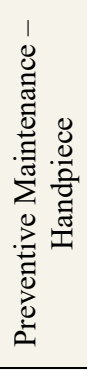 } & 27 & Request transportation of the module to the $[\mathrm{C}]$ & Customer \\
\hline & 28 & Send a module to the $[\mathrm{B}]$ & $\mathrm{TC}$ \\
\hline & 29 & Inspect the module & Company A \\
\hline & 30 & Calibrate the module & Company A \\
\hline & 31 & Request transportation of the module to the $[\mathrm{C}]$ & Company A \\
\hline & 32 & Send the module to the $[\mathrm{A}]$ & $\mathrm{TC}$ \\
\hline & 33 & Receive the calibrated module & Customer \\
\hline \multirow{10}{*}{ 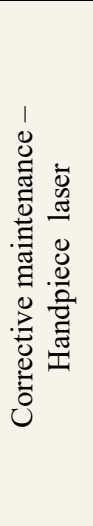 } & 34 & Request transportation of the module to the $[\mathrm{C}]$ & Customer \\
\hline & 35 & Send the module to the $[\mathrm{B}]$ & TC \\
\hline & 36 & Inspect the module & Company A \\
\hline & 37 & Repair the module and remove the faulty parts & Company A \\
\hline & 38 & Request transportation of the module to the $[\mathrm{C}]$ & Company A \\
\hline & 39 & Send the module to the $[\mathrm{A}]$ & $\mathrm{TC}$ \\
\hline & 40 & Receive the repaired module & Customer \\
\hline & 41 & Inspect and separate parts and consumables & Company A \\
\hline & 42 & Recondition parts/consumables & Company A \\
\hline & 43 & Dispose parts/consumables & WMC \\
\hline
\end{tabular}


Table 2. Continued...

\begin{tabular}{cclc}
\hline$\#$ & ID & Responsibilities & Stakeholder \\
\hline & 44 & Request transportation of the module to the [C] & Customer \\
& 45 & Send the module to the [B] & TC \\
& 46 & Inspect and separate parts and consumables & Company A \\
& 47 & Recondition parts/consumables & Company A \\
\hline
\end{tabular}

Warranty and service level agreement are key factors to define each stakeholder's responsibilities. The physical distance between customers and Company $\mathrm{A}$, and the costs/risks assumed for product and parts transportation are considered to define RL operation. The platform should be moved as little as possible, as it is the part with the highest added value, leading to great transportation risks.

\subsection{Reverse logistics services: Case B}

We identified four services for the infusion pump (Figure 3). The responsibilities of each stakeholder are shown in Table 3. The services are described as follows:

(I) Preventive maintenance: the clinical engineer user (CEU), responsible for managing the hospital's equipment, keeps a record of the preventive maintenance of the infusion pumps. When it is time for maintenance, the $\mathrm{CEU}$, assisted by operation users (i.e. nurses and physicians), separates and collects the equipment from hospital departments and contacts either Company B or third parties. In cases where hospitals have no CEU, the operator users should contact Company B or third parties themselves. A transport company is involved when the pumps is very far from the third-party responsible for the service. Preventive maintenance happens once a year;

(II) Corrective maintenance: as on the previous service, the corrective maintenance is carried out at Company B or third parties' facility. It is initiated when the operator user identifies a problem with the infusion pump. When applicable, the CEU is activated for assistance. The faulty equipment is collected internally, and third parties or Company B are involved. In the corrective maintenance, parts as the drop detector, electronic components, and batteries are replaced. Worn-out parts are redirected to Company B's headquarters that directs it to the waste management company (WMC);

(III) Collection upon the end of the product use (contract): when the contract expires and a new contract is not signed, the third parties count how many products are in the hospital and check their serial numbers before sending to Company B. After that, the product is inspected by the technicians, starting re-processing. After reconditioning, a new cycle of use starts. Worn-out parts are sent to the WMC;

(IV) Collection upon the product's EOL: this service usually starts through corrective maintenance, and only after careful inspection, the impossibility of repairing is eventually identified. After the recovery attempt fails, the pump is sent to Company B, where new inspection determines if it has reached the EOL. If it is the case, the Company sends the components to WMC.

Company B or third parties conduct the collection, inspection, maintenance, and redistribution. Company B is also responsible for reconditioning service. According to the Brazilian Health Regulatory Agency (Agência Nacional de Vigilância Sanitária, 2012; Brasil, 2001) only the Company that owns the product registration, or those authorized and appropriately trained by the Company, shall re-establish its technical and operational conditions for use. Company B and third parties instruct operator users and CEU not to perform any maintenance on the equipment. If the users do not return all the pumps at the end of the contract, the Company assumes the product is missing and charges the hospital. 


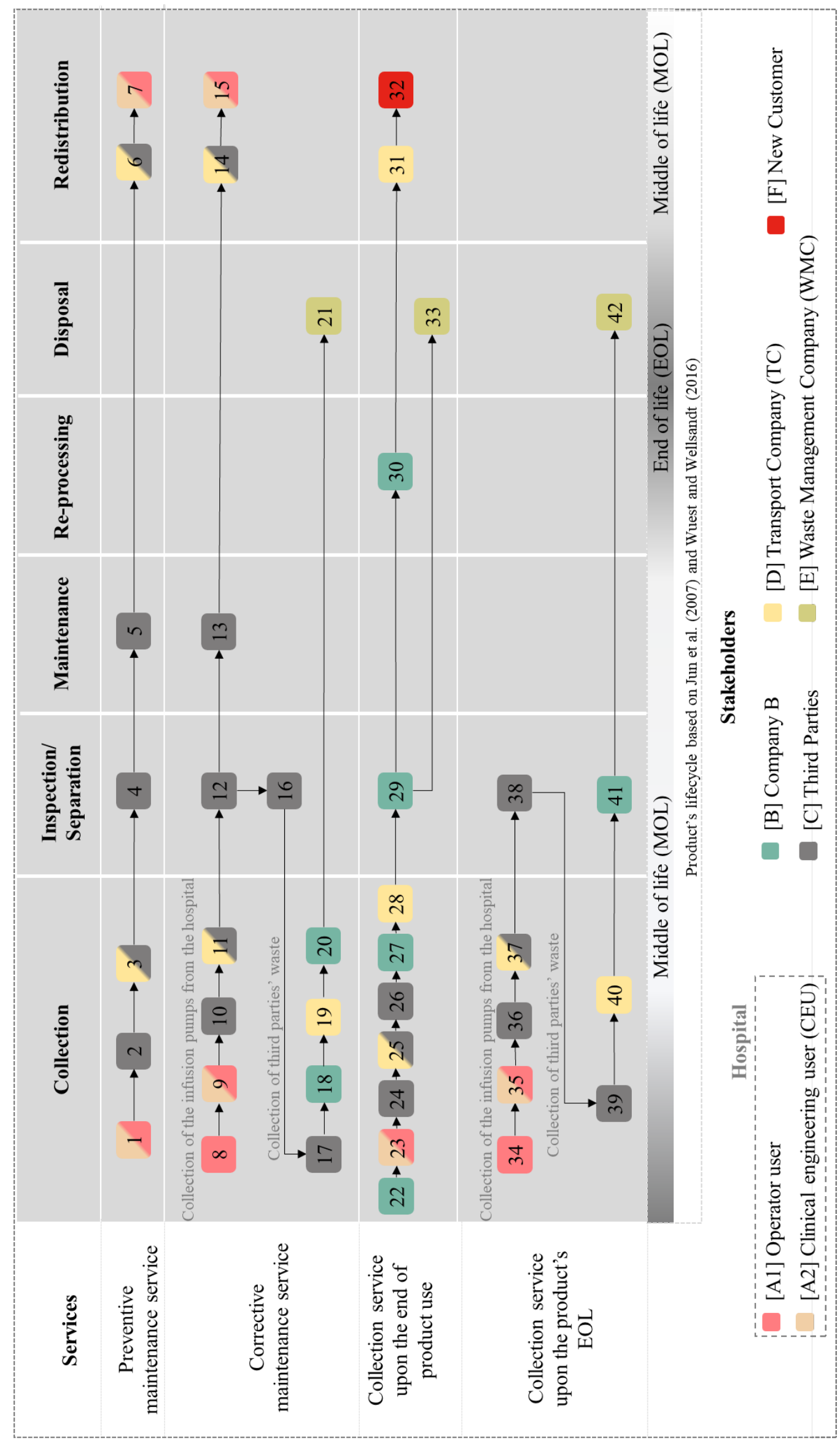

Figure 3. Responsibility map - Case B. 
Table 3. Stakeholder's responsibilities - Case B.

\begin{tabular}{|c|c|c|c|}
\hline \# & ID & Responsibilities & Stakeholder \\
\hline \multirow{7}{*}{ 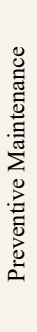 } & 1 & $\begin{array}{l}\text { Be attentive to the preventive maintenance schedule; separate and collect infusion pumps from the hospital sectors and } \\
\text { contact the }[\mathrm{C}]\end{array}$ & CEU/operator user \\
\hline & 2 & Prepare the collection on the infusion pump in the hospital & Third Parties \\
\hline & 3 & Transport the product & TC/Third Parties \\
\hline & 4 & Inspect the product & Third Parties \\
\hline & 5 & Conduct the preventive maintenance of the product & Third Parties \\
\hline & 6 & Transport the product to the hospital & TC/Third Parties \\
\hline & 7 & Receive the product & CEU/operator user \\
\hline \multirow{14}{*}{ 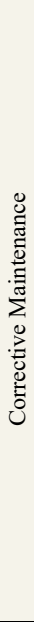 } & 8 & Detect problems on the product and inform the [A2] & Operator user \\
\hline & 9 & Separate and collect the product from hospital sectors, contact the $[\mathrm{C}]$ and inform if about the problem & CEU/operator user \\
\hline & 10 & Prepare the collection on the product in the hospital & Third Parties \\
\hline & 11 & Transport the product & TC/Third Parties \\
\hline & 12 & Inspect the product & Third Parties \\
\hline & 13 & Conduct the corrective maintenance of the product & Third Parties \\
\hline & 14 & Transport the product to the hospital & TC/Third Parties \\
\hline & 15 & Receive the product & CEU/operator user \\
\hline & 16 & Remove damaged components and replace consumables (waste) & Third Parties \\
\hline & 17 & Contact the $[\mathrm{B}]$ to return the waste & Third Parties \\
\hline & 18 & Prepare the collection of the Stakeholder's waste [C] & Company B \\
\hline & 19 & Transport the waste & $\mathrm{TC}$ \\
\hline & 20 & Receive the waste and send it to the $[\mathrm{E}]$ & Company B \\
\hline & 21 & Dispose of the waste & WMC \\
\hline \multirow{12}{*}{ 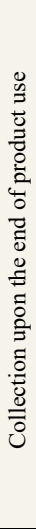 } & 22 & Contact the $[\mathrm{A} 2]$ and $[\mathrm{C}]$ and inform it about the termination of the contract & Company B \\
\hline & 23 & Separate and collect products from hospital sectors & CEU/operator user \\
\hline & 24 & Prepare the collection of the product in the hospital & Third Parties \\
\hline & 25 & Transport the product & TC/Third Parties \\
\hline & 26 & Check the number of infusion pumps collected and inform the $[\mathrm{B}]$ & Third Parties \\
\hline & 27 & Prepare the collection of the product from the [C] & Company B \\
\hline & 28 & Transport the product to the $[\mathrm{B}]$ & $\mathrm{TC}$ \\
\hline & 29 & Inspect the product; separate and send damaged components to the [E], and send the product to reconditioning & Company B \\
\hline & 30 & Recondition the product and send it to a new customer & Company B \\
\hline & 31 & Transport product to the $[\mathrm{F}]$ & $\mathrm{TC}$ \\
\hline & 32 & Receive the infusion pump & New customer \\
\hline & 33 & Dispose of waste & WMC \\
\hline \multirow{9}{*}{ 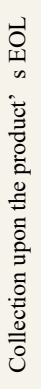 } & 34 & Detect a problem in the product and inform the [A2] & Operator user \\
\hline & 35 & Separate and collect product from hospital sectors; contact the $[\mathrm{C}]$ and inform it about the problem & CEU/operator user \\
\hline & 36 & Prepare the collection of the product in the hospital & Third Parties \\
\hline & 37 & Transport the product & TC/Third Parties \\
\hline & 38 & Inspect the product & Third Parties \\
\hline & 39 & Contact the $[\mathrm{B}]$ to return the product & Third Parties \\
\hline & 40 & Transport the product & $\mathrm{TC}$ \\
\hline & 41 & Inspect the product and send it to the [E] & Company B \\
\hline & 42 & Dispose of parts and components (waste) & WMC \\
\hline
\end{tabular}

\section{Discussion}

Our results suggest that each agent that composes the system holds specific responsibilities to ensure multiple uses of products and components, enabling the circularity of PSS in the healthcare industry. While the customer, personified by the physician, nurses or CEU, is the main trigger for RL services, the PSS provider is the main responsible for restoration activities. Therefore, the stakeholder and responsibility maps provide an integrated perspective on RL to improve the system's coordination. It expands the limited view of considering just the customer-provider relationship. 
By mapping and comparing both cases, we identified some contingency factors to define responsibilities in the RL of PSS. The size and weight of the component to be restored influences the strategy for moving products or people. In Company A, when handpiece needs maintenance, they are dispatched to the manufacturer. Meanwhile, if the platform, which is much larger and heavier, needs maintenance, the technical assistant visits the clinic. There is no single way of structuring RL activities to enable PSS, i.e. its implementation is contextspecific and may require adaptation to contingency factors.

Operating RL systems demand infrastructure and human resources, mainly if the service offered to clients sited far from the Company. Company B's employees stated that the activities related to maintenance and parts replacement are the organization's greatest expenses. In this regard, an important contingency factor when planning RL of PSS relates to the distance between manufacturer and customer. Company B hires third-party companies to ensure that maintenance is provided at every region while meeting the service level agreement. This strategy enables the solution in different regions. It is an important decision to make if a company plans to offer PSS in continental countries like Brazil.

Another factor observed is the influence of the product's life cycle on the RL activities carried out in a PSS. Usually, studies include RL as an activity performed at the EOL phase (Jun et al., 2007). In the cases studied, the $\mathrm{RL}$ is conducted during the MOL and EOL since goods are moved back in the value chain to capture available value. In this sense, organizations must take a holistic view of the PSS' life cycle, as supported by Wuest \& Wellsandt (2016). The product may be returned to the PSS provider, but not necessarily because it has reached its EOL. The customer may wish to terminate the contract or desire an updated version of the equipment (such as in trade-in service). A product that achieves the end of its use time can be traded-in, restored, and directed to a new customer. Therefore, the services constituting a particular PSS often aim to keep the product in its MOL for as long as possible. This statement is directly linked to slowing resource loops in a CE (Bocken et al., 2016).

Keeping products at a higher utility level is one of the circular principles (Ellen MacArthur Foundation, 2013). In both cases, preventive and corrective maintenance services increase the product's operating time and continuously use it. Through different strategies, products in Case A and B are redistributed to a second-hand market. Company A does this through the trade-in service. Company B ensures a new cycle of use for the infusion pump after the service level agreement cancellation.

The RL systems need to comply with increasingly strict responsibility policies related to healthcare waste and Waste of Electro-Electronic Equipment (WEEE). In Brazil, stakeholders respond to the National Policy on Solid Waste (Brasil, 2010); in Europe, the WEEE (European Union, 2012) prevail. In any case, the correct disposal of EEE (electro-electronic equipment) is required. Company A and B coordinate the proper disposal of broken products with WMC for functional and economic reasons. From the CE perspective, the WEEE industry has attracted significant attention, mainly because this waste is increasing globally and strategies to minimize its impacts need to be considered (Ongondo et al., 2011). In addition to durable EEEs, PSS providers should also consider consumables (e.g. infusion sets) in LR activities. After use, they become hospital waste due to its short life cycle characteristics. However, in case B, the collection of infusion sets is out of the PSS offering. This might be related to the fact that in Brazil the legal responsibility for managing this type of waste belongs to healthcare waste generators (Brasil, 2005), i.e. clinics and hospitals described in the cases. From the CE perspective, the WEEE industry has been gaining great prominence, especially since this type of waste is increasing globally and strategies to minimize its impacts need to be taken.

Therefore, although the case studies represent a rich depiction of RL activities' roles and responsibilities, Cases A and B involve some services that still lead to high use of resources. For instance, when Company A's customers wish to purchase an updated version of the equipment (V2), they need to buy new laser handpiece, as the new version does not support the previous platform modules. Moreover, the PSS of Case B relies on the continuous provision of infusion sets to charge its customers, but the EOL of such items is out of the solution's scope. In collaboration with different stakeholders, the companies of both cases are still on their way to reach the CE. In this context, it is necessary that all components be part of the RL and not only the most valuable ones.

\section{Conclusions}

This study consolidated the RL services, the stakeholders and their responsibilities in two PSS cases in the healthcare industry. Given the RL services, stakeholders' role and responsibilities should be clearly defined, especially aiming a CE. The findings represent good practices in the application of LR on PSS. Reliable RL services may improve circularity as it enables systematic prioritization and product recovery processes.

This research provides a clear contribution to practitioners since the maps can be used as models for RL system implementation and improvement. Different business model configurations and influence of contingency factors may require different stakeholders roles holding diverse responsibilities. Having a multiple stakeholder approach 
of the RL system helps organizations to operate in complex value networks. Moreover, it clarifies that the agents involved in the reverse value chain should participate in PSS planning and implementation. Previous studies have highlighted that for managers of focal companies, it is essential to have clear documentation of the roles and responsibilities of players (Parida et al., 2019).

For theory, this research clarifies the RL role in enabling PSS business models for the CE. It provides detailed descriptions and discussions in the healthcare business domain. The discussions raised from both cases clarify how stakeholders allow recovery systems. RL is framed as a support process for more strategic decisions. Thus, a critical challenge is to identify the RL potential to operate new services that enable business models that provide recurrent income, increased availability of medical equipment for the hospital, and promote more health with a smaller environmental impact than traditional business.

This study addresses the need to get to the detailed practical aspects of RL system responsibilities. The limitation pointed out for this study is that even though multiple stakeholders' roles and responsibilities were mapped and clarified, this research has only considered the perspective of individuals from Company A and B. Future studies should conduct multiple case studies in order to generalize the results. It is necessary to continue looking for the stakeholders' responsibilities, the potential benefits, and synergic interactions between all agents. Such efforts should aim at the RL reaching the maturity level we have counted on forward logistics, enabling the closed loop of resources required by a CE.

\section{Acknowledgements}

This study was supported by São Paulo Research Foundation (FAPESP) under the processes 2017/06144-5 and 2017/27144-3, and the Higher Education Personnel Improvement Coordination (Capes) - Finance Code 001. The opinions, hypotheses and conclusions or recommendations expressed in this material are of the responsibility of the authors and do not necessarily reflect the views of FAPESP and Capes.

\section{References}

Agência Nacional de Vigilância Sanitária - ANVISA. (2012). Nota técnica $N^{\circ} 05 / 2012 / G Q U I P / G G T P S / A N V I S A$. Brasília.

Associação Brasileira da Indústria de Dispositivos Médicos - ABIMO. (2021). Relatório setorial ABIMO: dados consolidados de 2020 e perspectivas 2021. São Paulo.

Azzine Shiratori, E. K., Hofmann Trevisan, A., \& Mascarenhas, J. (2021). The customer journey in a product-service system business model. Procedia CIRP, 100, 313-318. http://dx.doi.org/10.1016/j.procir.2021.05.072.

Bocken, N. M. P., de Pauw, I., Bakker, C., \& van der Grinten, B. (2016). Product design and business model strategies for a circular economy. Journal of Industrial and Production Engineering, 33, 308-320. http://dx.doi.org/10.1080/21681015.2016.1172124.

Brasil. Agência Nacional de Vigilância Sanitária - ANVISA. (2001). Resolução-RDC/ANVISA nº 25 de 15 de fevereiro de 2001. Dispõe sobre a importação, comercialização e doação de produtos para saúde usados e recondicionados. Diário Oficial [da] República Federativa do Brasil, Brasília.

Brasil. Conselho Nacional do Meio Ambiente - CONAMA. (2005). Resolução n ${ }^{0}$ 358, de 29 de abril de 2005. Dispõe sobre o tratamento e a disposição final dos resíduos dos serviços de saúde e dá outras providências. Diário Oficial [da] República Federativa do Brasil, Brasília.

Brasil. (2010). Lei n 12.305. Política Nacional de Resíduos Sólidos (PNRS). Diário Oficial [da] República Federativa do Brasil, Brasília.

Chierici, E., \& Copani, G. (2016). Remanufacturing with upgrade PSS for new sustainable business models. Procedia CIRP, 47, 531-536. http://dx.doi.org/10.1016/j.procir.2016.03.055.

Copani, G., \& Behnam, S. (2020). Remanufacturing with upgrade PSS for new sustainable business models. CIRP Journal of Manufacturing Science and Technology, 29, 245-256. http://dx.doi.org/10.1016/j.cirpj.2018.10.005.

Damha, L. G., Trevisan, A. H., Costa, D. G., \& Costa, J. M. H. 2019. How are end-of-life strategies adopted in product-service systems? A systematic review of general cases and cases of medical devices industry. Proceedings of the Design Society: International Conference on Engineering Design, 1, 3061-3070. https://doi.org/10.1017/dsi.2019.313.

Ellen MacArthur Foundation. (2013). Towards the circular economy: economic and business rationale for an accelerated transition. Cowes. https://doi.org/10.1162/108819806775545321.

European Union. (2012). Directive 2012/19/EU of the European Parliament and of the Council on waste electrical and electronic equipment (WEEE), L 197/38. Official Journal of the European Union, Brussels. http://dx.doi.org/10.3000/19770677.L_2012.197.eng.

Feist, E. (2021). Cascading Loop Creation: a case study of how digitalisation brings fashion retail product service systems, business partners, and customers together [Master's Thesis]. University of Borås, Borås.

Fernandes, S. C., Martins, L. D., \& Rozenfeld, H. (2019). Who are the stakeholders mentioned in cases of product-service system (PSS) design? Proceedings of the Design Society: International Conference on Engineering Design, 1(1), 3131-3140. https://doi.org/10.1017/dsi.2019.320. 
Fernandes, S. C., Pigosso, D. C. A., Mcaloone, T. C., \& Rozenfeld, H. (2020). Towards product-service system oriented to circular economy: a systematic review of value proposition design approaches. Journal of Cleaner Production, 257, 120507. http://dx.doi.org/10.1016/j.jclepro.2020.120507.

Fleischmann, M., Krikke, H. R., Dekker, R., \& Flapper, S. D. P. (2000). A characterisation of logistics networks for product recovery. Omega, 28(6), 653-666. http://dx.doi.org/10.1016/S0305-0483(00)00022-0.

Gnoni, M. G., Mossa, G., Mummolo, G., Tornese, F., \& Verriello, R. (2017). Supporting circular economy through use-based business models: the washing machines case. Procedia CIRP, 64, 49-54. http://dx.doi.org/10.1016/j.procir.2017.03.018.

Govindan, K., Palaniappan, M., Zhu, Q., \& Kannan, D. (2012). Analysis of third party reverse logistics provider using interpretive structural modeling. International Journal of Production Economics, 140(1), 204-211. http://dx.doi.org/10.1016/j.ijpe.2012.01.043.

Guzzo, D., Trevisan, A. H., Echeveste, M., \& Costa, J. M. H. (2019). Circular innovation framework: verifying conceptual to practical decisions in sustainability-oriented product-service system cases. Sustainability, 11(12), 3248. http://dx.doi.org/10.3390/su11123248.

Han, J., Heshmati, A., \& Rashidghalam, M. (2020). Circular economy business models with a focus on servitization. Sustainability, 12(21), 1-17. http://dx.doi.org/10.3390/su12218799.

Jun, H. B., Kiritsis, D., \& Xirouchakis, P. (2007). Research issues on closed-loop PLM. Computers in Industry, $58,855-868$. http://dx.doi.org/10.1016/j.compind.2007.04.001.

Kjaer, L. L., Pigosso, D. C. A., Niero, M., Bech, N. M., \& McAloone, T. C. (2019). Product/service-systems for a circular economy: the route to decoupling economic growth from resource consumption? Journal of Industrial Ecology, 23(1), 22-35. http://dx.doi.org/10.1111/jiec.12747.

Meier, H., Roy, R., \& Seliger, G. (2010). Industrial Product-Service systems-IPS². CIRP Annals, 59(2), 607-627. http://dx.doi.org/10.1016/j.cirp.2010.05.004.

Moultrie, J., Sutcliffe, L., \& Maier, A. (2015). Exploratory study of the state of environmentally conscious design in the medical device industry. Journal of Cleaner Production, 108, 363-376. http://dx.doi.org/10.1016/j.jclepro.2015.06.014.

Mun, I., \& Kantrowitz, A. (2008). On the right track. Retrieved in 2019, April 25, from https://www.hospitalmanagement.net/features/feature43134/

Ongondo, F. O., Williams, I. D., \& Cherrett, T. J. (2011). How are WEEE doing? A global review of the management of electrical and electronic wastes. Waste Management, 31, 714-730. http://dx.doi.org/10.1016/j.wasman.2010.10.023.

Osterwalder, A., \& Pigneur, Y. (2010). Business model generation: a handbook for visionaries, game changers, and challengers Hoboken: John Wiley \& Sons.

Parida, V., Burström, T., Visnjic, I., \& Wincent, J. (2019). Orchestrating industrial ecosystem in circular economy: a two-stage transformation model for large manufacturing companies. Journal of Business Research, 101, 715-725.

http://dx.doi.org/10.1016/j.jbusres.2019.01.006

Pialot, O., Millet, D., \& Bisiaux, J. (2017). "Upgradable PSS": clarifying a new concept of sustainable consumption/production based on upgradablility. Journal of Cleaner Production, 141, 538-550. http://dx.doi.org/10.1016/j.jclepro.2016.08.161.

Pourabdollahian, G., \& Copani, G. (2015). Development of a PSS-oriented business model for customized production in healthcare Procedia CIRP, 30, 492-497. http://dx.doi.org/10.1016/j.procir.2015.02.158.

Rosa, P., Sassanelli, C., \& Terzi, S. (2019). Towards circular business models: a systematic literature review on classification frameworks and archetypes. Journal of Cleaner Production, 236, 117696. http://dx.doi.org/10.1016/j.jclepro.2019.117696.

Sousa-Zomer, T. T., Magalhães, L., Zancul, E., \& Cauchick-Miguel, P. A. (2018). Exploring the challenges for circular business implementation in manufacturing companies: an empirical investigation of a pay-per-use service provider. Resources, Conservation and Recycling, 135, 3-13. http://dx.doi.org/10.1016/j.resconrec.2017.10.033.

Stickdorn, M., \& Schneider, J. (2011). This is service design thinking: basics, tools, cases. Hoboken: John Wiley \& Sons.

Swanson, L. (2001). Linking maintenance strategies to performance. International Journal of Production Economics, $70(3)$, 237244. http://dx.doi.org/10.1016/S0925-5273(00)00067-0.

Tukker, A. (2015). Product services for a resource-efficient and circular economy: a review. Journal of Cleaner Production, 97, 7691. http://dx.doi.org/10.1016/j.jclepro.2013.11.049.

Wastling, T., Charnley, F., \& Moreno, M. (2018). Design for circular behaviour: considering users in a circular economy. Sustainability, 10(6), 1-22. http://dx.doi.org/10.3390/su10061743.

World Health Organization - WHO. (2003). Medical device regulations: global overview and guiding principles. Geneva: WHO.

Wuest, T., \& Wellsandt, S. (2016). Design and development of Product Service Systems (PSS): impact on product lifecycle perspective. Procedia Technol., 26, 152-161. http://dx.doi.org/10.1016/j.protcy.2016.08.021.

Xing, K., Rapaccini, M., \& Visintin, F. (2017). PSS in healthcare: an under-explored field. Procedia CIRP, 64, $241-246$. http://dx.doi.org/10.1016/j.procir.2017.03.068.

Yip, M. H., Phaal, R., \& Probert, D. R. (2015). Characterizing product-service systems in the healthcare industry. Technology in Society, 43, 129-143. http://dx.doi.org/10.1016/j.techsoc.2015.05.014.

Yin, R. K. (2009). Case Study Research: Design and Methods. (4th Ed.). Thousand Oaks, CA: Sage. 
Appendix 1. Research protocol based on Osterwalder \& Pigneur (2010), Swanson (2001), and Fleischmann et al. (2000).

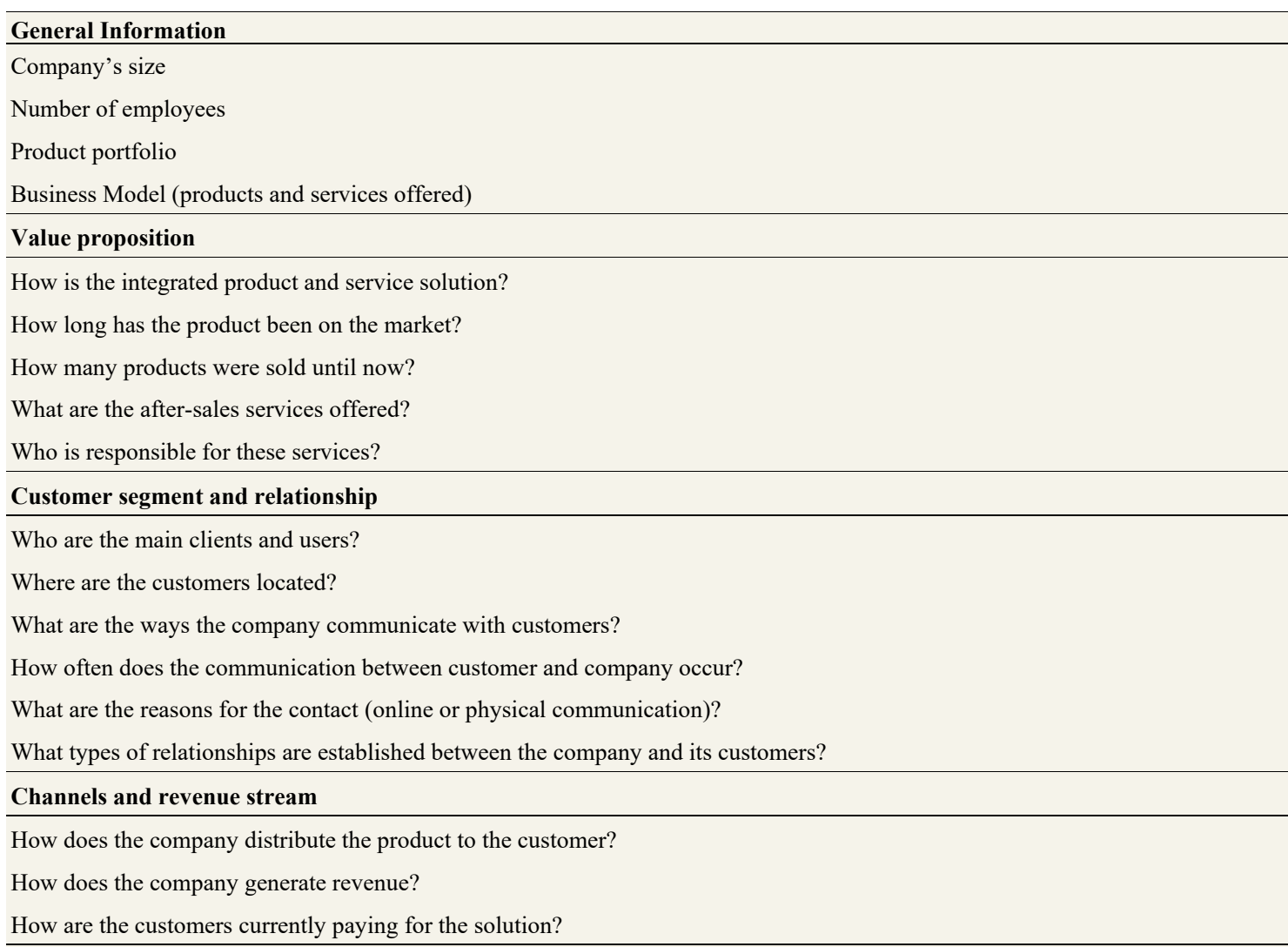

\section{Key resources, costs, activities, and partnerships}

What are the main physical, financial, human, and intellectual resources?

What are the most important costs when operating the business model?

What are the main processes related to the solution offered?

What are the main partnerships?

Does the company outsource any service or product's parts?

\section{Training and maintenance}

What types of training does the company offer and which stakeholders are involved?

Where and when does the training sessions take place?

What types of maintenance does the company offer?

Is the customer able to conduct periodic maintenance on its own?

Where is the maintenance performed and which stakeholders are involved?

\section{Reverse logistics}

How is the collection process carried out?

What type of pre-collection preparation does the user need to do?

Where does the inspection / separation process take place?

What are the product reprocessing options (e.g. refurbishment, remanufacturing, repair, recycling)?

Who is responsible for the product disposal?

Where are the parts and components discarded?

Are users able to dispose the product?

Who is responsible for the product re-distribution?

Which stakeholders are involved with the RL activities?

What extra activities are involved in the collection, inspection, re-processing, disposal, and re-distribution? 